drugs are rather less specific than is often assumed, and also suggest a role for calcium entry blockers of non-cardiogenic shock states However, the major importance of the book is in bringing together much of the work being done on the role of opioids in the pathogenesis of shock in different aetiologies. The acceptance of the quest for a unifying concept involving the central nervous system represents a major advance in shock research, but whether the endorphin system is the link is far from settled. It is unfortunate that, with only a few notable exceptions, much of the work reported is of selfperpetuating experiments pursuing changes that may be of statistical rather than of biological significance. There seems to be an overwhelming need for more clinical studies, and it is for this reason that this volume (despite its high price of $\mathfrak{f 4 1 )}$ is recommended as food for thought to all those interested in the care of the critically ill.

R A LITTLE

MRC Trauma Unit University of Manchester

\section{Bone and Joint Disease in the Elderly}

V Wright (ed) pp $305 £ 20.00$

Edinburgh: Churchill Livingstone 1983

There has been a need in the library for a good textbook on bone and joint disease in the elderly. This book, edited by Verna Wright, satisfies this need. It is an important work because it is not only geriatricians who treat elderly patients with arthritis. There is an excellent chapter from the Manchester unit on the epidemiological appraisal of bone and joint disease emphasizing that the elderly do want to regain their status which has disappeared through lack of mobility. Obviously the chapters on osteoarthritis, rheumatoid arthritis and polymyalgia rheumatica are mandatory. Howard Bird's chapter on osteoarthritis is easily readable and covers the subject well. The chapter on rheumatoid arthritis concentrates on the disease in general rather than in the elderly. More information could have been given perhaps on the group of elderly rheumatoids, often male, who do badly in the course of the disease. Professor Dan McCarty's chapter on CPPD crystal deposition disease is masterly and fully comprehensive. Other connective tissue disorders have fallen to Madison, Martin and Scott, and they detail these conditions briefly and well. Benedix's long chapter on the association of rheumatic diseases and rheumatic symptoms with cancer is fascinating, but as his conclusions are that there is little evidence of new links, it might have been wiser to have shortened this chapter and to have given the previous one more space. The chapter on metabolic bone disease and osteoporosis is well written by Nordin and Exton-Smith. Drugs in the elderly are covered in two chapters: one is an excellent summary chapter from Ian Haslock, and the second is a chapter from Marshall Pickup where emphasis is placed on pharmacokinetics and drug monitoring. It would impose a major strain on our resources if we were to monitor blood levels on everybody receiving drugs.

The next three chapters are on rehabilitation. There is a most useful chapter from Ann Chamberlain on the availability of aids to help mobility and to improve the external environment. This is followed by a rather dull chapter on physiotherapy which shows the problems of trying to be critical in an area where very few trials have been done. The chapter on aids and appliances duplicates the chapter on mobility, but is well illustrated. Finally, there is a chapter on orthopaedic surgery which perhaps overemphasizes the importance of orthopaedic surgery in the treatment of the elderly.

This book represents an excellent summary of orthopaedic rheumatological medicine and rehabilitation, but it lacks consistency of emphasis on the elderly and there is no chapter on soft tissue rheumatism - a common problem in old age.

HEDLEY BERRY

Consultant Rheumatologist King's College Hospital, London

\section{Soft Tissue Ossification}

\section{J M Connor pp 146 DM110}

Berlin: Springer-Verlag 1983

The author is an expert on fibrodysplasia ossificans progressiva; in addition to giving an excellent description of that disease, he provides us in small compass with a marvellous collection of the conditions causing bone formation in soft tissue. The first chapter comprises the general differential diagnosis of soft tissue calcification, with a somewhat compressed table of causes. Thereafter the book is confined, as its title indicates, to ossification. Readers will find answers to a variety of unsuspected problems. What is 'tacking on the crow' or 'Charley horse'? Where is the 'cobbler's' bone or the ossification in the 35-metre divers of Acapulco? Even speculative solutions to the predicaments of Lot's wife and the Gorgon's victims are offered.

Many disorders, such as ossification in trauma, tumours and neurological disorders, are covered in surprising detail for such a small book.

Fibrodysplasia ossificans progressiva is inherited as a Mendelian autosomal dominant trait in which neither the function of the gene nor the mechanism whereby it produces its effect is known. The author believes that the condition represents a genetic defect in the regulatory mechanism of certain mesenchymal cells. 
The references are generally recent, apposite and extensive. The latter part of the book consists of valuable discussions on experimental production of ectopic bone and the regulation of osteogenesis.

This is not only a comprehensive monograph on an important subject, but an eminently readable book showing clarity of expression found all too infrequently these days. It will prove of the greatest value to orthopaedic surgeons, rheumatologists, radiologists and others interested in the soft tissues.

DENNIS STOKER

Consultant Radiologist

Royal National Orthopaedic Hospital, London

\section{Atlas of the Ear by Scanning \\ Electron Microscopy. Yasuo Harada}

pp $231 £ 29.95$ Lancaster: MTP Press 1983

Picture books with the stereoscopic elegance of scanning EM photographs are particularly appealing, but once the first pleasure of wandering through the surreal landscape of the inner ear has passed there remain the worrying questions: for whom is the book intended, and what does it achieve?

In fact this atlas shows little of anything that is new or has not been revealed before. There is no account of the technique used to produce these lovely pictures, which would be valuable for the serious student wishing to emulate what he sees. Scanning EM is an end in itself only from an aesthetic point of view, and the lack of any description of the role of transmission electronmicroscopy, or any account of the way in which the two techniques of ultrastructural examination complement one another, is a deficiency. There is next the question of balance. Snippets of physiology tell us about otolith function - but why this when there is no account, for instance, of cochlear function? Pathological pictures are highly selective, treating a small handful of disorders. No, the serious worker will not find a comprehensive account of any whole subtopic and must look to other works. There are a number of inaccuracies. On page 107 figure 74 should be 78, and in figure 101 the label to a Deiter's cell extends to one of Hensen's, contradicting the preceding textual description of the outer tunnel. 'Sensory' otitis media on page 207 surely should be 'secretory' otitis media, and this error is echoed in the list of contents.

The book is a collection of pictures that have accumulated during the author's valuable research work on the ear. The justification for its production seems to be no greater than the feeling that these should be available for inspection; in itself this is a worthy motive, but the lack of cohesion and the failure to use the pictures within a more comprehensive framework do sadly mar the value of the book. At a price of nearly $£ 30$ it must be considered a rather extravagant ornamental luxury and not essential to every otological bookshelf.

\section{HAROLD LUDMAN Consultant ENT Surgeon King's College Hospital, London}

\section{The Physiology of Hemostasis}

Derek Ogston pp $378 \quad £ 19.95$

London: Croom Helm 1983

My only criticism of this book by the Regius Professor of Physiology in Aberdeen, which is published in London, is the author's preference for the American spelling of 'haemostasis'. Otherwise it is uniformly excellent in concept and execution. The whole field of normal haemostasis, including physiological variations, is covered in 13 chapters. My own special areas of interest (the biochemistry of factor $\mathbf{X}$ activation, and platelet function) are right up to date and well referenced.

I unhesitatingly recommend this book as a general introduction to haemostasis and as a source of specialist information, either directly or indirectly through the references, for students, teachers and researchers in this rapidly advancing field of investigation.

\section{Senior Lecturer in Haematology Royal Free Hospital, London}

\section{A Medical Bibliography (Garrison \& Morton) \\ 4th edn L T Morton pp 1000 \\ $£ 45.00$ Aldershot, Hants: Gower 1983}

The first edition of what is affectionately known as 'Garrison-Morton' was mainly compiled during World War II, and was miraculously published in 1943. Undeterred by the repeated bombing of London, Mr Leslie Morton produced an expanded and annotated edition of Fielding H Garrison's slender 'check-list of texts illustrating the history of medicine'. The subsequent editions of 1954 and 1970 in turn became inseparable companions for all who were seriously interested in the evolution of the medical specialties and the key publications on which progress has depended.

More than $\mathbf{4 0}$ years after he first embarked on his enormous task, Mr Morton's energies are happily undiminished. The new edition now fills 1000 pages, and its 7830 entries include 760 that are new. The unfortunate need to delete a few hundred of those in the previous edition provides the medical bibliophile with a new hobby - to spot the discards and meditate upon them. For example, in the general section on microbiology, we note the loss of Flügge and his early textbook of 1883 , and, more sadly for the British reader, 